\title{
An investigation of the nonlinear creep damage accumulation of different materials: Application of a novel damage model
}

\author{
$\mathrm{Xu} \mathrm{Zhao}^{1}$, Xuming $\mathrm{Niu}^{1}$, Yingdong Song ${ }^{1}$, and Zhigang Sun ${ }^{1}$ \\ ${ }^{1}$ Nanjing University of Aeronautics and Astronautics
}

June 4, 2021

\begin{abstract}
Variable creep load is one of the most important failure modes for hot-component of aero-engine. To accurately predict creep damage and remaining life, a novel nonlinear creep damage accumulation model is proposed based on the Wilshire function and isodamage line, which takes the influence of load history into account and uses ultimate tension strength to compensate the temperature effect. Experimental result of tests on four kinds of material were utilized to verify the accuracy of the proposed model and to compare it with existing models. It was determined that the novel model was better at predicting damage accumulation than all others model. Furthermore, the proposed model elucidates the evolutionary process of creep damage, and four cases of damage evolution process are discussed.
\end{abstract}

\section{Hosted file}

Manuscript.doc available at https://authorea.com/users/417892/articles/524812-aninvestigation-of-the-nonlinear-creep-damage-accumulation-of-different-materialsapplication-of-a-novel-damage-model

\section{Hosted file}

Table.docx available at https://authorea.com/users/417892/articles/524812-an-investigationof-the-nonlinear-creep-damage-accumulation-of-different-materials-application-of-anovel-damage-model

\section{Hosted file}

Figure.pdf available at https://authorea.com/users/417892/articles/524812-an-investigationof-the-nonlinear-creep-damage-accumulation-of-different-materials-application-of-anovel-damage-model 